\section{Epidemiology and Etiology of Mesothelioma}

Spyros A. Papiris and Charis Roussos
Contents

40.1 Mesothelioma ............... 473

40.2 Characteristics of Asbestos Fibers ......... 474

40.3 History of Asbestos Utilization and Exposure ... 474

40.4 Epidemiology of Mesothelioma ........... 474

40.5 Environmental Asbestos Exposure in the Metsovo Area of North-western Greece ......... 475

40.6 Malignant Pleural Mesothelioma in Turkey. Geographic Areas with Environmental Asbestos Exposure and Other Geographic Areas with Environmental Exposure to Erionite ...... 47

40.7 Other Geographic Areas with Natural Asbestos Deposits and Environmental Asbestos Exposure . 477

40.8 Etiology of Mesothelioma ............ 477

40.9 Simian Virus 40 and Mesothelioma ........ 477

40.10 Conclusion .................. 478

\subsection{Mesothelioma}

Malignant mesothelioma is a highly aggressive and almost invariably fatal tumor arising from the mesothelial cells that form the serosal lining of the pleura, pericardium, peritoneum, and tunica vaginalis. More than $80 \%$ of malignant mesotheliomas are pleural in origin. Peritoneal mesothelioma appears to be more common in heavily exposed individuals [1]. Most of malignant mesotheliomas in the western world develop in individuals with higher than background asbestos exposure and it is unlikely that low environmental exposure to asbestos is associated with more than negligible risk of mesothelioma [2]. Indeed, the incidence of mesothelioma appears clearly parallel to the more widespread use of asbestos observed worldwide during the last half century, and it is actually estimated that about $5 \%$ of asbestos workers develop this disease. Mesothelioma can develop 20 or more years after the first exposure, while the peak incidence is between 35 and 45 years after exposure. However, the latency period ranges from a minimum of about 5 years [3] to a maximum of 72 years, so that exposed individuals are at risk for all their lives [4]. Non-occupational asbestos exposure has also been associated with an increase incidence of mesothelioma $[5,6]$. In the USA, the incidence of mesothelioma, though difficult to be precisely determined, is estimated to be two to three thousand new cases per year [7]. However, it is estimated that the asbestos cancer epidemic may take as many as 10 million lives before asbestos is banned worldwide and exposures are brought to an end [8]. More recently, the oncogenic simian virus (SV) 40, a DNA virus of the family of papovaviridae, has also been implicated as a potential etiologic agent, though some controversy still exists [9]. Rare cases of mesothelioma have been associated with radiation exposure and the intravenous administration of the contrast medium Thorotrast [10]. Finally, in a restricted geographic area of three villages of Cappadocia, a region of central Anatolia in Turkey, more than $50 \%$ of all deaths are caused by pleural malignant mesothelioma. These cases are considered to be related to the erionite exposure, another non-asbestos mineral fiber, a type of fibrous zeolite commonly found in the stones of the houses of the villagers. This observation led to the recognition that erionite is one of the most potent chemical human carcinogens [11]. However, it is also known that approximately $20 \%$ of mesotheliomas occur in individuals with no history of asbestos exposure and only a small percentage of exposed individuals develop the disease, supporting the concept that genetic factors may play a significant role in its pathogenesis [12]. As appears from the above considerations, mesothelioma seems to have a complex etiology in which environmental carcinogens such as asbestos (by far the most important risk factor) and erionite, ionizing radiation, viruses, and possibly genetic factors act alone or in concomitance to induce malignancy [13]. Whatever the cause and because of its increasing incidence worldwide, the social impact of mesothelioma has become devastating, since no satisfactory treatment exists and survival time after diagnosis is usually less than 18 months. 


\subsection{Characteristics of Asbestos Fibers}

Asbestos is the general name given to certain naturally occurring hydrated magnesium silicate fibrous minerals that form under high pressure in the earth's crust and are commonly found around earthquake faults. Geologists divide asbestos fibers into two groups: (1) serpentines, which include chrysotile (white asbestos), and (2) amphiboles, which include amosite (brown asbestos), crocidolite (blue asbestos), tremolite, anthophyllite, and actinolite. Asbestos fibers have several unique physical properties, such as thermal resistance, tensile strength, acoustic insulation, and resistance to degradation by both acid and alkaline solutions. The aspect ratio (length-towidth ratio) is the distinguishing feature of a particle and classifies it as a fiber when it is 3 or greater. Asbestos degrades by splitting longitudinally into even smaller fibers. This physical characteristic enhances its insulation properties but also increases the fraction of fibers that deposit deeply in the lung when inhaled. Fiber deposition in the lung occurs through five aerodynamic mechanisms: impaction, sedimentation, interception, electrostatic precipitation, and diffusion. Impaction and sedimentation depend on the aerodynamic diameter of the fiber, interception is governed by fiber length, and electrostatic precipitation depends on the electrical charge of the fiber. Processing of asbestos fibers results in aerosols with relatively high levels of electrical charge. Amphibole fibers when inhaled align parallel to the axis of flow and deposit deeply in the lung at the level of the alveolar ducts. Serpentine fibers such as chrysotile when inhaled have a mixed flow pattern and are more frequently deposited at the airway bifurcations. The biologically active or inhalable asbestos particles are those with a diameter of less than $3 \mu \mathrm{m}$ and a length between 5 and $100 \mu \mathrm{m}$. Only $20 \%$ of asbestos fibers fall into this category and the most common is crocidolite.

\subsection{History of Asbestos Utilization and Exposure}

The word asbestos is derived from the Greek «asvestos» which means "inextinguishable or unquenchable" and reflects its resistance to heat and acid as well as its strength, durability, and flexibility. The Romans termed asbestos "amianthus" which means without miasma, undefiled

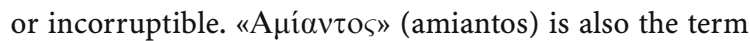
actually used by the modern Greeks for asbestos and "amianto" by the Italians. Asbestos has been used by humans since 4,000 years before the Christian Era [14]. One of its first applications was for wicks in lamps and candles. Subsequently, 2-3000 years BCE asbestos was used in clothes to embalm the bodies of the Egyptian pharaohs and in Finland it was used in the same period, 2,500 years
$\mathrm{BCE}$, to strengthen clay pots. Around 1000 years AD Mediterranean people used chrysotile from Cyprus and tremolite from north Italy to make cremation clothes, mats, and wicks for temple lamps. Three to four centuries later Marco Polo visited an asbestos mine in China. In the early 1700 s asbestos papers and boards were made in Italy. Subsequent applications were as insulating material in steam engines in the USA (1828), for helmet and jackets by the Parisian Fire Brigade (1853), and for brake linings by Ferodo in England (1896). At the turn of the twentieth century asbestos applications and consequently exposure increased exponentially. One of its last applications was in the insulation of the solid fuel boosters of the space shuttle.

\subsection{Epidemiology of Mesothelioma}

In the first half of the twentieth century mesotheliomas were so rare that even their existence was debated [15]. In a review of 47 thousand autopsies at the Massachusetts General Hospital from 1896 to 1947 no mesotheliomas were found [16]. However, between 1947 and 1990 about 100 mesotheliomas were observed, and now it is estimated, and probably underestimated, that there are two to three thousand new cases every year in the USA [15]. The modern history of mesothelioma begins with the publication of the article "Diffuse pleural mesothelioma and asbestos exposure in the northwestern Cape province" [17], implicating asbestos exposure in the development of mesothelioma. The authors described a region in South Africa of about 8,000 square miles where crocidolite (locally named "woolstone") was mined. The earliest mining was a "family job" where men quarried the rocks and women and children separated fiber from stone. The increasing demand of asbestos around the years of World War II brought the large companies into the process of mining and processing and resulted in much higher numbers of involved and exposed individuals. Wagner and coworkers identified, in 4 years, 33 cases of mesothelioma almost exclusively in people living around the areas of mine or mill. This pioneering work provided the first and strong evidence of an association between asbestos and mesothelioma. This work also laid the foundation for the definitive investigation of insulation workers in the USA by Irving Selikoff and coworkers [18]. Selikoff's studies demonstrated an enormously increased mortality in these workers and made clear that an epidemic of occupational cancer was under way [18]. In South Africa mining reached its peak in 1977 with more than 380,000 tons being exported and 20,000 miners employed in the industry. South Africa also has large deposits of chrysotile and amosite both of which have been mined extensively. In South Africa the work by Wagner and coworkers was continued, not without difficulties, by Webster (funding was discontinued and 
the report was denigrated) [14] who reported 232 cases of mesothelioma based on pathology reports sent to the $\mathrm{Na}$ tional Centre of Occupational Health [19] and by Zwi and coworkers who reported 1,347 cases diagnosed between 1976 and 1984 [20]. According to these reports, mesothelioma incidence in South Africa is amongst the highest in the world. It is 6 times higher than in England and at least as high as in Western Australia. The male/female ratio is $2.5 / 1$. The incidence in blacks, for obvious reasons, is particularly under reported. Zwi's 9-year study also showed a steady increase in mesothelioma incidence during those years. In South Africa a high proportion of mesotheliomas $(26 \%)$ is attributed to non-occupational, environmental origin, and among them 93\% originate from exposure to crocidolite. Non-occupational exposures to asbestos can be grouped into three main categories: paraoccupational (familial), neighborhood, and true environmental exposures [6]. Among all reported environmental cases more than $70 \%$ of women and children are affected. This is presumably related to the asbestos brought home in the hairs and clothes of the miners.

Overall more than 30 million tons of asbestos in its various forms have been mined worldwide in the past century. Actually, the worldwide asbestos production exceeds 2 million tons each year. The greatest asbestos producers are Russia, China, Canada, Brazil, Kazakhstan, and Zimbabwe. Canada is the largest asbestos-exporting country, exporting 300,000 tons of chrysotile annually. All forms of asbestos can cause benign pleural effusions, pleural plaques, round atelectasis, diffuse fibrothorax, asbestosis (interstitial diffuse fibrosing alveolitis), lung cancer, and mesotheliomas. Chrysotile accounts for $90 \%$ of the commercially used asbestos worldwide, with the amphiboles constituting the rest. The amphiboles and particularly crocidolite appear to be the most carcinogenic of the fibers [21] though according to Stayner and coworkers it seems prudent "to treat chrysotile with virtually the same level of concern as the amphibole forms of asbestos" [22]. Indeed, on a per fiber basis, the highest risks of lung cancer have been shown for chrysotile [23]. Asbestos exposure affects not only asbestos workers but also their families, users of asbestos products, and the public as asbestos is used in building materials and in heating and ventilating systems [8]. Exposed women develop mesothelioma at rates at least as high as men with the same exposures, though their overall numbers are much lower since fewer women have occupational exposures. Epidemiologic studies attempted to define occupational risks associated with mesothelioma. In a work of the 1980s it was shown that the greater relative risk (RR) was associated with insulation work $(R R=46)$, followed by employment in asbestos manufacture $(R R=6.1)$, heating trades $(R R=4.4)$, shipyards $(R R=2.8)$, and construction $(R R=2.0)$ [24]. Actually, asbestos is present in more than 3,000 manufactured products and justifiably constitutes one of the most pervasive environmental haz- ards in the world and is a real "health catastrophe". In many developed countries, in specific age groups, mesothelioma may account for $1 \%$ of all deaths. In addition to mesotheliomas, $5-7 \%$ of all lung cancers can be attributed to asbestos exposure. Peak production and usage of asbestos occurred in many countries during the 1960s, 1970s, and 1980s and, as mesothelioma can develop 20 or more years after the first exposure, with a peak incidence coming 35-40 years after exposure, the incidence of mesothelioma is expected to increase dramatically over the next few years peaking in the developed world in or around the year 2020. In Western Europe it is estimated that deaths from mesothelioma will increase from just over 5,000 per year in 1998 to about 9,000 by the year 2018 [25], a global estimation of a quarter of a million deaths over the next 35 years. Lung cancer deaths caused by asbestos may even be much higher if we accept a ratio 7:1 (lung cancer to mesotheliomas deaths) suggested by some investigators [26]. The International Labor Organization (ILO) estimated that at least 100,000 and maybe as many as 140,000 workers die each year from asbestos exposures resulting in cancer [27]. Current estimations report that the asbestos cancer epidemic may take as many as 10 million lives before asbestos is banned worldwide and exposures are brought to an end [8]. In this conservative estimation, it is assumed that asbestos exposure is going to cease and that the epidemic will run itself out [8]. However, the world's asbestos production seems to have stabilized at around 2 million tons/year (20012002 data) and a global ban on asbestos is far from occurring. In future decades, the health problem of asbestos exposure will also occur in developing countries where in recent years most asbestos industries have transferred their economic interests, where protection of workers and communities is scant or non-existent, and where the asbestos cancer epidemic will become even more devastating than in the developed world [8].

\subsection{Environmental Asbestos Exposure in the Metsovo Area of North-western Greece}

Inhabitants of four villages of the Metsovo area (Metsovo, Milia, Anilio, and Votonosi) in the Epirus region, north-western Greece (population of 4,250 inhabitants on the 1981 census and of 4,494 on the 1991 census) have been exposed, since childhood, to asbestos from a material used for whitewashing. This material locally called "luto" soil contains tremolite and had been used by practically all households until 1950-1960 [28-30]. This tremolite-containing whitewash was taken from outcrops in nearby hills, shaped into balls, and sold. Subsequently, the women of Metsovo crushed the balls into fine powder, boiled it in water, and applied it to 
the walls once or twice a year. During the extraction process, and particularly while crushing this material, a tremendous amount of fibers was released ( $>200$ fibers per $\mathrm{cm}^{3}$ ) and inhaled [31]. Tremolite fibers were indeed identified in the lung parenchyma of the exposed individuals in transbronchial lung biopsy specimens [32]. The exposure of inhabitants of Metsovo to tremolite has resulted in endemic pleural calcifications in at least half of the population $[29,30,33,34]$, a high incidence of malignant pleural mesothelioma [29, 30], sporadic cases of round atelectasis eventually related to the development of a previous benign asbestos pleural effusion [35], and lymphocytic alveolitis especially among inhabitants with pleural calcifications [36], but no diffuse fibrosing interstitial lung pneumonia (asbestosis). The combination of the above findings (and especially the mesothelioma and pleural calcifications) has been named "Metsovo lung" and has been established as an example of non-occupational exposure to tremolite. Metsovo exposure appears to be a unique kind of exposure, differing from the "usual" occupational or non-occupational exposures in the following aspects: (1) it was a "woman's job" and exposure eventually included their small children present during the in-house part of the process (very early in life exposure); (2) the exposure was not continuous; and (3) exposure was very heavy during crushing [37]. The use of "luto" soil gradually diminished during the next three decades and was finally abandoned in the early 1980s. The diminished use of "luto" whitewash was followed by a drop in the incidence of mesotheliomas in the area [37]. Actually it is expected that the "Metsovo mesothelioma epidemic" will fade away by the year 2020-2030, since the material has not been used since 1985 [37]. Environmental asbestos exposure has also been reported in several other geographic areas of Greece "outside Metsovo" [31].

\subsection{Malignant Pleural Mesothelioma in Turkey: Geographic Areas with Environmental Asbestos Exposure and Other Geographic Areas with Environmental Exposure to Erionite}

Turkey is a country with large natural asbestos deposits and a high prevalence of endemic asbestos-related pulmonary disease [38-41]. Asbestos-contaminated soil mixtures are commonly found in the rural areas around Eskisehir in central Anatolia, where they have been used for many years locally by the rural inhabitants to make a whitewash (in a strikingly similar way to the villagers of Metsovo, Greece) or stucco for the walls, floors, and roofs of the houses and also for baby powder, in pottery, or added to grape juice. These soil mixtures are known in Anatolia as "aktoprak" (white soil) or "çorak." Mineralogical analysis disclosed that besides tremolite (the most prominent asbestos type found as a contaminant of white stucco in these areas), chrysotile asbestos and, in certain districts (Mihaliççik and Edige), anthophyllite also contaminate white stucco [42]. The above-mentioned environmental exposure to asbestos as a cause of pleural mesothelioma has been documented in many studies [43-46]. Recently it has also been shown that this type of environmental exposure may be responsible for the very high incidence of mesothelioma observed in the villagers exposed, similar to the occupationally exposed asbestos cohorts [40].

In the Nevshehir region of Cappadocia, an informal ancient denomination for parts of central Anatolia, there are three villages, Karain, Tuzköy, and Sarihidir, with a population of around 5,000 people. It has been recently shown that up to $50 \%$ of deaths in Karain, between 1970 and 1994, and 36\% of deaths in the other two villages, between 1980 and 1994, were due to pleural and, less frequently, peritoneal mesothelioma [11]. Mesothelioma also caused $78 \%$ of deaths found in a cohort of 162 Karain villagers who had emigrated to Sweden [46]. These mesotheliomas are attributed to erionite, a fibrous type of zeolite present in stones used to build these villages and mined from nearby caves, and villagers exposed to it have the highest incidence of mesothelioma in the world. Erionite belongs to the mineralogical group of zeolites, a group of hydrated aluminosilicates of alkali and alkaline earths. Zeolites occur in cavities in basic volcanic rocks and in other late-stage hydrothermal environments. Erionite fibers are found in rocks and soils of areas of the above-referred villages, which like many other places in Cappadocia, Turkey, are characterized by ancient rock dwellings and caves dug in soft volcanic tuff. This type of dwelling favors the continuous exposure of inhabitants to erionite fibers. Epidemiologic and experimental data have shown that erionite fibers have the highest carcinogenic potency among any other fibers so far studied [47-50]. Erionite fibers also have a very strong fibrogenic potential. High concentrations of erionite fibers have been found in air samples and in lung tissue and bronchoalveolar lavage fluid of residents from these villages [51]. However, epidemiologic studies in this particular geographic area demonstrated that mesothelioma developed more frequently in certain families and in specific homes, where entire families had died from the disease. Interestingly, in Karlik, a village with a population of about 1,500, $1 \mathrm{~km}$ south of Karain, and built with the same stones used to build Karain, no mesothelioma was found except in a woman from Karain who relocated there, suggesting a strong genetic factor contributing to mesothelioma appearance in certain families. To investigate this hypothesis, an analysis of a sixgeneration extended pedigree of 526 individuals was conducted and it indicated that mesothelioma occurrence, at least in this area, can be explained by genetic 
susceptibility, which is probably transmitted in an autosomal dominant way [52]. In these cases erionite might be a cofactor in the cause of mesothelioma, in genetically predisposed individuals.

\subsection{Other Geographic Areas with Natural Asbestos Deposits and Environmental Asbestos Exposure}

Environmental asbestos exposure is also common in some other rural parts of the world, including other geographic areas of Greece "outside Metsovo" [31], Cyprus, where asbestos deposits contain mostly chrysotile with some tremolite contamination [53], and New Caledonia [54] and Corsica, where both chrysotile and tremolite can be found $[55,56]$. In all of the above areas an increasing incidence of mesothelioma was described confirming the association between natural asbestos deposits and mesothelioma in non-occupationally exposed populations.

\subsection{Etiology of Mesothelioma}

After the publication of the "milestone" study by Wagner and coworkers describing mesotheliomas in subjects who lived in the Blue Hills region of Northwest Cape Province of South Africa, and its confirmation by several other studies in the same geographic area and worldwide, asbestos is to be considered the primary etiologic agent of mesothelioma. All asbestos fibers are injurious and carcinogenic for both animals and human, crocidolite (blue asbestos) and amosite (brown asbestos) being the most harmful. In addition several cases of mesothelioma have been associated with erionite fiber exposure, radiation therapy such as in the treatment of Hodgkin's disease [10], chronic inflammation [57], and the Simian virus 40 (SV40), a contaminant of early polio vaccines that were provided to millions of individuals in Europe and in the USA between 1955 and 1963 [58]. Organic chemicals, including polyurethane, polysilicone, ethylene oxide, N-methyl-n nitrosourethane diethylstilbestrol, and mineral oil, have been shown to cause mesothelioma in rodents [59]. Also other non-asbestos fibers such as fiberglass have been implicated in mesothelioma development in animals [60]. Furthermore, the occurrence of mesothelioma among subjects with blood relations suggests that genetic factors might play a role in determining the susceptibility to asbestos-related cancer [61]. Finally, it is also known that approximately $20 \%$ of mesotheliomas occur in individuals with no history of asbestos exposure or to any other putative etiologic factor and that only a small percentage of asbestos-exposed individuals develop the disease, supporting the concept that genetic factors may play some role in mesothelioma development [12] (Table 40.1).

\subsection{Simian Virus 40 and Mesothelioma}

Simian virus 40 is a small, circular, 5,243-bp, doublestranded DNA polyomavirus of the family of papovaviridae of monkey origin. SV40 was found by Sweet and Hilleman to be one of the viruses infecting rhesus and cynomolgus monkey kidney cells used for the preparation of polio and other vaccines [62]. Soon after, it was shown that SV40 had the capacity to infect and transform human cells in vitro [63]. Experimental studies have shown subsequently the potentiality of wild-type SV40 viruses to induce mesotheliomas with at least the same potency as asbestos fibers [64-66]. The primary mechanism of the SV40 oncogenic effect is thought to occur through its linkage with the large $\mathrm{T}$ cell antigen Tag and the subsequent inactivation of two tumor suppressor genes, p53 and retinoblastoma protein, $\mathrm{Rb}$, as well as of their products, p107 and p130. The result is a combination of loss of cell cycle regulation associated with genomic instability, cell transformation, immortalization, and tumor development [58]. Hundreds of millions of SV40-contaminated poliovirus vaccine preparations, prepared in Macaca kidney cells, were used between 1955 and 1962 to vaccinate people in USA, Europe, the former USSR, Mexico, Japan, and Central America. Both the inactivated Salk subcutaneous vaccine and the live attenuated Sabin vaccine were contaminated, which were both prepared from macaque rhesus monkey cell cultures. Soon after SV40 was reported to be oncogenic in hamsters, the US government

Table 40.1. Etiologic factors of mesothelioma

\begin{tabular}{|c|c|c|c|c|c|}
\hline Fibers & Radiation & Chemicals & Inflammation & Viruses & Genetic factors \\
\hline $\begin{array}{l}\text { Asbestos (chrysotile, } \\
\text { amosite, crocidolite, } \\
\text { tremolite, anthophyllite, } \\
\text { actinolite) } \\
\text { Erionite } \\
\text { Fiberglass? }\end{array}$ & $\begin{array}{l}\text { Ionizing radiation } \\
\text { Thorotrast }\end{array}$ & $\begin{array}{l}\text { Polyurethane } \\
\text { Polysilicone } \\
\text { Ethylene oxide } \\
\text { N-Methyl-n } \\
\text { nitrosourethane } \\
\text { diethylstilbestrol } \\
\text { Mineral oil }\end{array}$ & TBC pleuritis? & Simian virus $40 ?$ & $\begin{array}{l}\text { Autosomal } \\
\text { dominant way } \\
\text { in Cappadocia }\end{array}$ \\
\hline
\end{tabular}


disposed that all newly produced polio vaccine should be free of the contaminant virus but they did not remove the already contaminated ones from the vaccine program. In the following decades SV40 DNA was detected in a variety of human tumors such as mesotheliomas, osteosarcomas, other bone tumors, and brain tumors, and several epidemiologic and experimental studies have suggested a role of SV40 alone or in combination with asbestos fibers [67] in determining an increase of certain human tumors including mesotheliomas. However, the National Institutes of Health and the Food and Drug Administration special joint workshop failed to reach an agreement on the role of SV40 as a potential human carcinogen [68]. Disagreement was based on: (1) the lack of detection of SV40 DNA in human mesothelioma experiments by Shah [69]; (2) the SV40 DNA detection in normal tissue and body fluids; and (3) the inadequacy of epidemiologic data. Furthermore, a recent study has brought more evidence against a role for SV40 infection in human mesotheliomas and the high risk of false-positive PCR results due to the presence of SV40 sequences in common laboratory plasmids [9]. The authors conclude "that clinicians should continue to consider asbestos exposure as the most likely and most thoroughly established etiological factor in individuals with mesothelioma" [9].

\subsection{Conclusion}

Unequivocally the history of mesothelioma parallels that of asbestos exposure. The estimation that the asbestos cancer epidemic will cause 10 million deaths past and present renders the need to reach urgently a global ban on asbestos an issue of highest priority, so that the asbestos cancer epidemic will not become more devastating and will not continue indefinitely.

\section{Key Points}

Mesothelioma is a highly aggressive and invariably fatal tumor arising from mesothelial cells that form the serosal lining of the pleura, and less frequently of the pericardium, peritoneum, or tunica vaginalis.

- Almost all mesotheliomas develop in individuals with higher than background asbestos exposure. Asbestos is present in more than 3,000 manufactured products and constitutes one of the most pervasive environmental hazards in the world. Asbestos exposure affects not only asbestos workers but also their families, users of asbestos products, and the public as it is exposed to building materials and asbestos in heating and ventilating systems.

\section{References}

1. Britton M. The epidemiology of mesothelioma. Semin Oncol 2002;29:18.

2. Ware A, Price B. Mesothelioma trends in the United States: an update based on surveillance, epidemiology, and end results program data for 1973 through 2003. Am J Epidemiol 2004;159:107.

3. Booth SJ, Weaver EJM. Malignant pleural mesothelioma five years after domestic exposure to blue asbestos. Lancet 1986;i:435.

4. Bianchi C, Giarelli L, Grandi G, Brollo A, Ramani L, Zuch C. Latency periods in asbestos-related mesothelioma of the pleura. Eur J Cancer Prevent 1997;6:162.

5. Hansen J, de Klerk NH, Musk AW, Hobbs TMS. Environmental exposure to crocidolite and mesothelioma. Exposure-response relationships. Am J Respir Crit Care Med 1998;157:69.

6. Orenstein MR, Schenker MB. Environmental asbestos exposure and mesothelioma. Curr Opin Pulm Med 2000;6:371.

7. Price B. Analysis of current trends in United States mesothelioma incidence. Am J Epidemiol 1997;145:211.

8. LaDou J. The asbestos cancer epidemic. Environ Health Perspect 2004;112:285.

9. López-Rios F, Illei PB, Rusch V, Ladanyi M. Evidence against a role for SV40 infection in human mesotheliomas and high risk of false-positive PCR results owing to presence of SV40 sequences in common laboratory plasmids. Lancet 2004;364:1157.

10. Weissmann LB, Corson JM, Neugut AI, Antman KH. Malignant mesothelioma following treatment for Hodgkin's disease. J Clin Oncol 1996;14:2098.

11. Baris B, Demir AU, Shehu V, Karakoca Y, Kisacik G, Baris YI. Environmental fibrous zeolite (erionite) exposure and malignant tumors other than mesothelioma. J Environ Pathol Toxicol Oncol 1996;15:183.

12. Huncharek M. Genetic factors in the aetiology of malignant mesothelioma. Eur J Cancer 1995;31:1741.

13. Carbone M, Kratzke RA, Testa JR. The pathogenesis of mesothelioma. Semin Oncol 2002;29:2.

14. Abratt RP, Vorobiof DA, White N. Asbestos and mesothelioma in South Africa. Lung Cancer 2004;45S:S3.

15. Hughes RS. Malignant pleura mesothelioma. Am J Med Sci 2005;329:29.

16. Mark EJ, Yokoi T. Absence of evidence for a significant background incidence of diffuse malignant mesothelioma apart from asbestos exposure. Ann N Y Acad Sci 1991;643:196.

17. Wagner J, Sleggs C, Marchand P. Diffuse pleural mesothelioma and asbestos exposure in the northwestern Cape province. Br J Ind Med 1960;17:260.

18. Selikoff IJ, Hammond EC, Churg J. Asbestos exposure and neoplasia. JAMA 1964;188:22.

19. Webster I. Asbestos and malignancy. S Afr Med J 1973;47:165.

20. Zwi AB, Reid G, London SP, Kielkowski D, Sitas F, Becklake MR. Mesothelioma in South Africa 1976-1984: incidence and case characteristics. Int J Epidemiol 1989;18:320.

21. Niklinski J, Niklinska W, Chyczewski E, Laudanski J, Naumnik W, Chyczewski L, Pluygers. The epidemiology of asbestos related diseases. Lung Cancer 2004;45S:S7.

22. Stayner LT, Dankovic DA, Lemen RA. Occupational exposure to chrysotile asbestos and cancer risk: a review of the amphibole hypothesis. Am J Public Health 1996;86:179.

23. Dement JM, Brown DP, Okun A. Follow-up study of crysotile asbestos textile workers: cohort mortality and casecontrol analysis. Am J Ind Med 1994;26:431. 
24. MacDonald AD, MacDonald JC. Malignant mesothelioma in North America. Cancer 1980;46:1650.

25. Peto J, Decarli A, La Vecchia C, Levi F, Negri E. The European mesothelioma epidemic. Br J Cancer 1999;79;566.

26. ILO. Introductory report: decent work-safe work. Geneva: International Labour Organization. 2002.

27. Howie RM. Asbestos and cancer risk. Ann Occup Hyg 2001;45:335.

28. Langer AM, Nolan RP, Constantopoulos SH, Moutsopoulos HM. Association of Metsovo lung and pleural mesothelioma with exposure to tremolite-containing whitewash. Lancet 1987;i:319.

29. Constantopoulos SH, Malamou-Mitsi V, Goudevenos J, Papathanasiou MP, Pavlidis NA, Papadimitriou CS. High incidence of malignant pleura mesothelioma in neighbouring villages of north-west Greece. Respiration 1987;51:266.

30. Constantopoulos SH, Saratzis N, Goudevenos J, Kontogiannis D, Karantanas A, Katsiotis P. Tremolite whitewashing and pleural calcifications. Chest 1987;92:709.

31. Constantopoulos SH, Theodorakopoulos P, Dascalopoulos G, Saratzis NA, Sideris K. Metsovo lung outside Mestovo: endemic pleural calcifications in the ophiolite belts of Greece. Chest 1991;99:1158.

32. Constantopoulos SH, Goudevenos J, Saratzis N, Langer AE, Selikoff IJ, Moutsopoulos HM. Metsovo lung: pleural calcifications and restrictive lung function in north-western Greece; environmental exposure to mineral fiber as etiology. Environ Res 1985;38:391.

33. Bazas T, Bazas B, Kitas D, Gilson JC, McDonald JC. Pleural calcification in northwest Greece [letter]. Lancet $1981 ; 1: 254$

34. Bazas T, Oakes D, Gilson JC, Bazas B, McDonald JC. Pleural calcification in north-west Greece. Environ Res 1985;38:239.

35. Papiris SA, Maniati MA, Sakellariou K, Gosios C, Kontogiannis $\mathrm{D}$, Constantopoulos $\mathrm{H}$. Round atelectasis and Metsovo lung. Chest 1993;103:1759.

36. Constantopoulos SH, Dalavanga YA, Sakellariou K, Goudevenos J, Kotoulas OB. Lymphocytic alveolitis and pleural calcifications in nonoccupational asbestos exposure: protection against neoplasia? Am Rev Respir Dis 1992;146:1565.

37. Sakellariou K, Malamou-Mitsi V, Haritou A, Koumpaniou C, Stachouli C, Dimoliatis ID, Constantopoulos SH. Malignant pleura mesothelioma from nonoccupational asbestos exposure in Metsovo (north-west Greece): slow end of an epidemic. Eur Respir J 1996;9:1206.

38. Karakoca Y, Emri S, Cangir AK, Baris YI. Environmental pleural plaques due to asbestos and fibrous zeolite exposure in Turkey. Indoor Built Environ 1997;6:100.

39. Emri S, Demir A, Dogan M, Akay H, Bozkurt B, Carbone $\mathrm{M}$, Baris I. Lung disease due to environmental exposures to erionite and asbestos in Turkey. Toxicol Lett 2002;127:251.

40. Metintas S, Metintas M, Ucgun I, Oner U. Malignant mesothelioma due to environmental exposure to asbestos. Follow-up of a Turkish cohort living in a rural area. Chest 2002;122:2224.

41. Emri S, Demir AU. Malignant pleural mesothelioma in Turkey, 2000-2002. Lung Cancer 2004;45S:S17.

42. Dogan M, Emri S. Environmental health problems related to mineral dusts in Ankara and Eskisehir, Turkey. Yerbilimleri 2000;22:149.

43. Yazicioglu S, Ilcayto R, Balci K, Sayli BS, Yorulmaz B. Pleural calcification, pleural mesotheliomas and bronchial cancers caused by tremolite dust. Thorax 1980;35:564.

44. Hillerdal G, Baris YI. Radiological study of pleural changes in relation to mesothelioma in Turkey. Thorax 1983;38:443.
45. Baris YI. Asbestos and erionite related disease. Ankara, Turkey. Semith Ofset Mat Com 1987;8.

46. Metintas M, Hilllerdal H, Metintas S. Malignant mesothelioma due to environmental exposure to erionite: followup of a Turkish cohort. Eur Respir J 1999;13:523.

47. Baris Y, Simonato L, Artvinli M, et al. Epidemiological and environmental evidence of the health effects of exposure to erionite fibers: a 4 year study in the Cappadocian region of Turkey. Int J Cancer 1987;39:10.

48. Maltoni C, Minardi F, Morisi L. Pleural mesotheliomas in Spargue-Dawley rats by erionite: first experimental evidence. Environ Res 1982;29:238.

49. Davis JM, Bolton RE, Miller BG, Niven K. Mesothelioma dose response following intraperitoneal injection of mineral fiber. Int J Exp Pathol 1991;72:263.

50. Wagner JC, Skidmore JW, Hill RJ, Griffiths DM. Erionite exposure and mesotheliomas in rats. $\mathrm{Br} \mathrm{J}$ Cancer 1985;51:727.

51. Dumortier P, Çoplü L, Broucke I, Emri S, Selcuk T, de Maerelaer V, De Vuyst P, Baris I. Erionite bodies and fibers in bronchoalveolar lavage fluid (BALF) of residents from Tuzköy, Cappadocia, Turkey. Occup Environ Med 2001;58:261.

52. Rousdy-Hamady I, Siegel J, Emri S, Testa JR, Carbone M. Genetic-susceptibility factor and malignant mesothelioma in the Cappadocian region of Turkey. Lancet 2001;357:444.

53. McConnochie K, Simonato L, Mavrides P, Christofides P, Pooley FD, Wagner JC. Mesothelioma in Cyprus: the role of tremolite. Thorax 1987;42:342.

54. Goldberg P, Goldberg M, Marne MJ, Hirsch A, Tredaniel J. Incidence of pleural mesothelioma in New Caledonia: a 10 year survey (1978-1987). Arch Environ Hlth 1991;46:306.

55. Luce D, Brochard P, Quenel P, Salomon-Nekiriai C, Goldberg P, Billon-Galland MA, Goldberg M. Malignant pleural mesothelioma associated with exposure to tremolite. Lancet 1994;344:8939.

56. Rey F, Boutin C, Steinbauer J, Viallat JR, Alessandroni P, Jutisz P, Di Giambattista D, Billon-Galland MA, Hereng P, Dumortier $\mathrm{P}$, et al. Environmental pleural plaques in an asbestos exposed population of northeast Corsica. Eur Resp J 1993;6:978.

57. Roviaro GC, Sartori F, Calabro F, Varoli F. The association of pleural mesothelioma and tuberculosis. Am Rev Respir Dis $1982 ; 126: 569$.

58. Cerrano PG, Jasani B, Filiberti R, Neri M, Merlo F, De Flora S, Mutti L, Puntoni R. Simian virus 40 and malignant mesothelioma. Int J Oncol 2003;22:187.

59. Bass P, Schouwink H, Zoetmulder FA. Malignant pleural mesothelioma. Ann Oncol 1998;9:139.

60. Stanton MF, Wrench C. Mechanisms of mesothelioma induction with asbestos and fibrous glass. J Natl Cancer Inst 1972;48:797.

61. Bianchi C, Brollo A, Ramani L, Bianchi T, Giarelli L. Familial mesothelioma of the pleura: a report of 40 cases. Ind Health 2004;42:235.

62. Sweet BH, Hilleman MR. The vacualating SV40. Proc Soc Exp Biol Med 1960;105:420.

63. Shein HM, Enders JF. Transformation induced by simian virus 40 in human renal cell cultures. 1. Morphology and growth characteristics. Proc Natl Acad Sci U S A 1962;48:1164.

64. Carbone M, Lewis AM Jr, Matthews BJ, Levine AS, Dixon K. Characterization of hamster tumors induced by simian virus 40 small t deletion mutants as true histiocytic lymphomas. Cancer Res 1989;49:1565.

65. Cicala C, Pompetti F, Carbone M. SV40 induces mesotheliomas in hamsters. Am J Pathol 1993;142:1524. 
66. Carbone M, Fisher S, Powers A, Pass HI, Rizzo P. New molecular and epidemiological issues in mesothelioma: role of SV40. J Cell Physiol 1999;180:167.

67. Bocchetta M, Di Resta I, Powers A, Fresco R, Tosolini A, Testa JR, Pass HI, Rizzo P, Carbone M. Human mesothelial cells are unusually susceptible to simian virus 40- mediated transformation and asbestos cocarcinogenicity. Proc Natl Acad Sci U S A 2000;97:10214.

68. Brown F, Lewis AM Jr (eds). Simian virus 40 (SV40): a possible human polyomavirus. Basel: Karger, 1998.

69. Shah KV. Search for SV40 in human mesothelioma. In: Brown F, Lewis AM Jr (eds) Simian Virus 40 (SV40): A Possible Human Polyomavirus. Basel: Karger, 1998:68. 